\section{The highs and lows of $\mathrm{ETCO}_{2}$}

\section{Sam McMillan}

\section{THE PHYSIOLOGY OF VENTILATION}

The rhythmic pattern of breathing is controlled by nuclei in the pons and medulla (the respiratory centres) but the output can be overridden to a certain extent by the cortex, for example, during periods of stress. These nuclei receive input from central and peripheral chemoreceptors.

Central chemoreceptors are situated near the ventral surface of the medulla and are sensitive to the partial pressure of $\mathrm{CO}_{2}\left(\mathrm{PCO}_{2}\right)$ of blood. They respond to the changes in the $\mathrm{pH}$ of extracellular fluid (ECF) or cerebrospinal fluid (CSF) that are caused by changes in $\mathrm{PCO}_{2}$ as $\mathrm{CO}_{2}$ diffuses from cerebral capillaries. Peripheral chemoreceptors are situated in the carotid and aortic body. They respond to decreased $\mathrm{PO}_{2}$ and increased $\mathrm{H}^{+}$ (decreased $\mathrm{pH}$ ) and $\mathrm{PCO}_{2}$.

$\mathrm{PCO}_{2}$ of blood is the primary factor controlling ventilation under normal circumstances. The peripheral chemoreceptor response is more rapid but less marked than the central chemoreceptor response. The hypoxic response (response to low $\mathrm{PO}_{2}$ ) is small and is not really apparent until the patient is severely hypoxaemic.

Normal $\mathrm{PaCO}_{2}$ in the conscious healthy patient is between $35 \mathrm{mmHg}$ and $45 \mathrm{mmHg}$ - this can be considered as normocapnia. Normocapnia is maintained by minute ventilation (minute volume) and thus by the respiratory frequency and tidal volume of the patient. A number of patient or disease factors can lead to hypoventilation (elevated $\mathrm{PCO}_{2}$ or hypercapnia) in the conscious patient including: neurological disorders, obstructive upper airway disease, pleural space disease and severe pulmonary disease. These factors will also cause hypoventilation in an anaesthetized patient but even a healthy patient will hypoventilate to a certain degree under anaesthesia because almost all anaesthetic agents have respiratory depressant effects. This is likely to be due to depression of the respiratory centres via the $\mathrm{GABA}_{\mathrm{A}}$ receptor effects of most anaesthetic agents. These effects are generally dose dependent and can compromise the animal's ability to adequately ventilate their lungs leading to an increase in $\mathrm{PCO}_{2}$.

\section{MONITORING VENTILATION}

As $\mathrm{CO}_{2}$ diffuses so rapidly from the blood into the alveoli it can be used as a measure of the adequacy of alveolar ventilation. To get a true indication of how well an animal is ventilating, an arterial blood gas is required for the measurement of the partial pressure of arterial $\mathrm{CO}_{2}$ $\left(\mathrm{PaCO}_{2}\right)$. However arterial $\mathrm{CO}_{2}$ levels are approximately equal to alveolar $\mathrm{CO}_{2}$ levels which can be more easily measured. Alveolar gases are the last gases to be expelled during expiration and therefore end-tidal $\mathrm{CO}_{2}\left(\mathrm{ETCO}_{2}\right)$ monitoring via capnography will give a breath to breath approximation of $\mathrm{PaCO}_{2}$ and therefore the adequacy of ventilation. Hypoventilation can be classified as $\mathrm{PaCO}_{2}$ (or $\mathrm{ETCO}_{2}$ ) over $45 \mathrm{mmHg}$ and some anaesthetists would instigate intermittent positive-pressure ventilation (IPPV) for any patient whose $\mathrm{PaCO}_{2}$ rose above this level. Other anaesthetists would argue that the adverse effects of IPPV are worse than the adverse effects of mild hypoventilation, and the subsequent hypercapnia, so would instigate IPPV at a $\mathrm{PaCO}_{2}$ (or $\mathrm{ETCO}_{2}$ ) of $50-55 \mathrm{mmHg}$ This is termed permissive hypercapnia.

This lecture will cover the physiology of ventilation and how to use capnography in practice including types of capnography and troubleshooting.

\section{KEY LEARNING OBJECTIVES}

- Understand the physiology of ventilation

- Understand the use of capnography for the assessment of ventilation status in small animals

- Understand the types of capnography available and troubleshooting of the capnograph

\section{MULTIPLE CHOICE QUESTIONS}

1. Which of the following monitors is most important when monitoring ventilation?
(A) A suitably trained veterinary nurse
(B) Capnograph
(C) Pulse oximeter
(D) Arterial blood gases

2. What is considered to be normal $\mathrm{ETCO}_{2}$ ?
(A) $35-45 \mathrm{cmH}_{2} \mathrm{O}$
(B) $15-30 \mathrm{mmHg}$
(C) $35-45 \mathrm{mmHg}$
(D) $15-30 \mathrm{cmH}_{2} \mathrm{O}$

3. What can hypoventilation be defined as?
(A) $\mathrm{ETCO}_{2}<35 \mathrm{mmHg}$
(B) $\mathrm{ETCO}_{2}>45 \mathrm{~mm} \mathrm{Hg}$
(C) $\mathrm{ETCO}_{2}<45 \mathrm{mmHg}$
(D) $\mathrm{ETCO}_{2}>60 \mathrm{mmHg}$ 